\title{
Glucose Mass Transfer in Alcoholic Fermentation Using Stirred Beds of Immobilized S. Cerevisiae Cells
}

\section{Anca-Irina Galaction ${ }^{1}$, Marius Turnea ${ }^{1}$ and Dan Cascaval ${ }^{2 *}$}

${ }^{1}$ Gr.T. Popa University of Medicine and Pharmacy of lasi, Faculty of Medical Bioengineering, Department of Biomedical Sciences, M. Kogalniceanu 9-13, 700454 lasi, Romania

${ }^{2}$ Gh. Asachi Technical University of lasi, Faculty of Chemical Engineering and Environmental Protection, Department of Biochemical Engineering, D. Mangeron 73, 700050 lasi, Romania

\begin{abstract}
The external and internal mass transfers of substrate have been analyzed for alcoholic fermentation using a bioreactor with mobile beds of immobilized yeast cells. The experiments have been carried out under glucose inhibition limitation for different sizes and concentrations of biocatalysts particle. By means of the substrate mass balance for a single particle of biocatalysts, considering the kinetic model adapted for the inhibitory effect of glucose, a specific mathematical model has been developed for describing the profiles of the substrate concentration in the outer and inner regions of biocatalysts and, implicitly, for estimating its mass flows in the liquid boundary layer surrounding the particle and inside the particle. The values of the mass flows are significantly influenced both by the internal diffusion velocity of substrate, and by the rate of the biochemical reaction of substrate consumption. These cumulated influences led to the appearance of "biological inactive region" near the particle centre, its magnitude varying from 0.34 to $1.22 \%$ from the overall volume of particles. The use of mixing diminished considerably the extent of this region compared to that recorded for similar substrate conversion in a fixed bed bioreactor.
\end{abstract}

Keywords: Diffusion; Mass transfer; Stirred bed; Immobilized cells; Glucose

Notations: $\mathrm{Bi}$ : Biot number; $\mathrm{C}_{\mathrm{C}}$ : Cells concentration, kg d.w.kg-1 $\mathrm{C}_{\mathrm{s}}$ : substrate concentration, $\mathrm{kg} \cdot \mathrm{m}^{-3} ; \mathrm{C}_{\mathrm{s}}$ : Substrate concentration at the biocatalyst particle surface, $\mathrm{kg} \cdot \mathrm{m}^{-3} ; \mathrm{C}_{\mathrm{sL}}$ : Substrate concentration in the liquid bulk, kg.m ${ }^{-3} ; \mathrm{C}_{\mathrm{SP}}$ : Substrate concentration inside the biocatalyst particle, kg. $\mathrm{m}^{-3}$; d: Impeller diameter, $\mathrm{m}$; $\mathrm{d}_{\mathrm{p}}$ : Biocatalyst particle diameter, $\mathrm{m} ; \mathrm{D}_{\mathrm{Se}}$ : Effective diffusivity, $\mathrm{m}^{2} \cdot \mathrm{s}^{-1} ; \mathrm{D}_{\mathrm{SL}}$ : liquid phase diffusivity, $\mathrm{m} . \mathrm{s}^{-1} ; \mathrm{K}_{\mathrm{I}}$ : Inhibition constant, $\mathrm{kg} \cdot \mathrm{m}^{-3} ; \mathrm{k}_{\mathrm{L}}$ : liquid phase mass transfer coefficient, $\mathrm{m} / \mathrm{s} ; \mathrm{K}_{\mathrm{M}}$ : Apparent Michaelis-Menten constant, kg.m $\mathrm{m}^{-3} ; \mathrm{n}_{\mathrm{L}}$ : External mass flow, $\mathrm{kg} \cdot \mathrm{m}^{-2} \cdot \mathrm{s}^{-1} ; \mathrm{n}_{\mathrm{p}}$ : Internal mass flow, $\mathrm{kg} \cdot \mathrm{m}^{-2} \cdot \mathrm{s}^{-1} ; \mathrm{N}$ : Rotation speed, $\mathrm{s}^{-1} ; \mathrm{R}_{\mathrm{p}}$ : Biocatalyst particle radius, $\mathrm{m} ; \mathrm{V}$ : Maximum biochemical reaction rate, $\mathrm{kg} \cdot \mathrm{m}^{-3} \cdot \mathrm{s}^{-1}$;

Greek Letters: $\varphi$ : Volumetric fraction of biocatalyst particles; $\phi$ : Thiele modulus; $\eta_{\mathrm{L}}$ : Liquid phase viscosity, $\mathrm{Pa} . \mathrm{s}^{-1} ; \rho_{\mathrm{L}}$ : Liquid phase density, kg.m $\mathrm{m}^{-3}$

\section{Introduction}

The new concept of "white biotechnology" has been promoted at the International Conference "European Bioperspectives - En Route to a Knowledge-Based Bio-Economy" (Cologne, Germany, May 31 June 12007 ) and proclaims that the use of renewable raw materials for biofuels production by low-expensive and ecofriendly biotechnologies constitutes one of the priorities of the industrial activities [1].

Included in the new biofuels class currently tested and used, bioethanol represents an attractive alternative to the conventional fossil fuels, its production by converting various substrates by free or immobilized cells of bacteria (Clostridium sp.) or yeasts (Saccharomyces $s p$., Zymomonas $s p$.) being intensively studied in the last two decades [2-4]. Glucose is the substrate with the fastest conversion rate in the bacterial or yeasts metabolic processes for bioethanol production. The bacteria or yeasts posses the ability to convert glucose under anaerobic conditions by Embden-Mereyhof-Parnas metabolic pathway, the main final products being the ethanol and carbon dioxide $[5,6]$. The efficiency of ethanol production by yeasts can be affected by glucose or ethanol concentration, due to the specific phenomenon of substrate or product inhibition. In these circumstances, the viability of $S$. cerevisiae population, the substrate consumption and ethanol biosynthesis rates are directly controlled by the cultivation conditions. An interesting result has been obtained by Nagodawithana and Steinkraus, the authors concluding that the addition of ethanol in a culture of $S$. cerevisiae induces less toxic effect than that generated by ethanol biosynthesized during the fermentation, the cells death occurring with lower rate in the former case [7]. This result could be explained by the presence of other metabolic products beside ethanol, these secondary products contributing to the amplification of its inhibitory phenomenon.

As it was previously concluded, the fermentation with immobilized cells could avoid the substrate inhibitory effect, the use of higher concentration of carbohydrates becoming possible, allows the easier recovery of biocatalysts and attenuates the reduction of the microbial activity $[1,4]$. Therefore, the biocatalysts can be reused for many fermentation cycles.

Among the bioreactors with immobilized biocatalysts, those with stirred/mobile beds are the most attractive ones, owing to their constructive and operational similitude to the well-known stirred bioreactors and, consequently, to the higher rates of heat and mass transfer that can be reached. But, as it can be observed from literature,

*Corresponding author: Dan Cascaval, Gh. Asachi Technical University of lasi, Faculty of Chemical Engineering and Environmental Protection, Department of Biochemical Engineering, D. Mangeron 73, 700050 lasi, Romania, Fax: 0040232271311; E-mail: dancasca@ch.tuiasi.ro

Received November 14, 2011; Accepted January 18, 2012; Published January 21, 2012

Citation: Galaction A, Turnea M, Cascaval D (2012) Glucose Mass Transfer in Alcoholic Fermentation Using Stirred Beds of Immobilized S. Cerevisiae Cells. Single Cell Biol 1:101. doi:10.4172/ 2168-9431.1000101

Copyright: (C) 2012 Galaction A, et al. This is an open-access article distributed under the terms of the Creative Commons Attribution License, which permits unrestricted use, distribution, and reproduction in any medium, provided the original author and source are credited. 
most of the experiments on alcoholic fermentation with immobilized cells have been carried out in fixed bed bioreactors in continuous, semi continuous or fed-batch systems [2-4,8-16]. The fixed beds of immobilized cells have been preferred due to the higher sensitivity of the immobilized cells or enzymes to the shear forces generated by the impellers.

Our previous studies on alcoholic fermentation performed in a bioreactor with stirred beds of immobilized S. cerevisiae cells in alginate indicated that it is possible to reach very efficient mixing without or with minimum loss of biocatalysts physical integrity by selecting the optimum impellers combination [17]. These studies have been dedicated to the analysis of the medium hydrodynamics for different biocatalysts particles sizes and volumetric fractions using seven types of radial impellers. The results have been directly correlated with the shear effects on the immobilized cells particles.

The previous experiments are continued by investigating the external and internal mass transfer of glucose under substrate inhibition limitation and by developing a new mathematical model describing the distribution of substrate concentration inside the biocatalysts particle.

\section{Materials and Methods}

\section{Equipments}

The experiments have been carried out in $5 \mathrm{~L}$ ( $4 \mathrm{~L}$ working volume) laboratory bioreactor (Biostat A, B. Braun Biotech International), with computer-controlled and recorded parameters $[18,19]$.

The mixing equipment consists of two pitched bladed turbines of $64 \mathrm{~mm}$ diameter and three baffles. The inferior impeller has been placed at $64 \mathrm{~mm}$ from the bioreactor bottom. The superior impeller was placed on the same shaft at a distance of $32 \mathrm{~mm}$ from the inferior one. The rotation speed was maintained at $250 \mathrm{rpm}$, this value avoiding the "cave" formation at the broths surface, solid phase deposition at the bioreactor bottom and mechanical disruption of the biocatalysts particles. According to the previous results, these impellers combination and rotation speeds were found to be the optimum ones for the investigated fermentation system [17]. Any mechanical damage of the biocatalyst due to the shear forces was recorded during the experiments.

In the experiments, immobilized S. cerevisiae cells in alginate have been used. The immobilization has been carried out by cells inclusion into the alginate matrix, respecting the method given in literature [11]. The following diameters of the biocatalyst spherical particles have been obtained: 4, 4.6 and $5.2 \mathrm{~mm}$. The volumetric fraction of the immobilized cells into the medium was varied between 0.07 and 0.40 .

The composition of the medium was: glucose 100 g.L $\mathrm{L}^{-1}, \mathrm{KH}_{2} \mathrm{PO}_{4} 5$ $\mathrm{g} \cdot \mathrm{L}^{-1},\left(\mathrm{NH}_{4}\right)_{2} \mathrm{SO}_{4} 2 \mathrm{~g} \cdot \mathrm{L}^{-1}, \mathrm{MgSO}_{4} 0.2 \mathrm{~g} \cdot \mathrm{L}^{-1}$, yeast extract $2 \mathrm{~g} \cdot \mathrm{L}^{-1}$, tap water to the prescribed volume [20]. The fermentations have been carried out at $28^{\circ} \mathrm{C}$.

The process evolution has been analyzed by means of the variation of glucose concentration in the liquid during the fermentation. The glucose concentration has been measured by high performance liquid chromatography technique (HPLC) with a Phenomenex Rezex ROA column (7.8 $\mathrm{mm}$ diameter, $300 \mathrm{~mm}$ length), provided with the refractive index detector RID-10A. The mobile phase was a solution of $5 \times 10^{-3} \mathrm{~N}$ sulfuric acid with a flow rate of $0.6 \mathrm{~mL} / \mathrm{min}$. The analysis temperature was of $65^{\circ} \mathrm{C}$.

\section{Theoretical aspects and mathematical models}

Internal diffusion is important especially for the biocatalysts obtained by cells or enzymes immobilization inside of an inert matrix. In this case, the substrate has to migrate to the cells or enzymes through non-linear channels, its diffusion being described by the effective/ apparent diffusion coefficient or diffusivity. The rate of the biochemical reactions occurring inside the biocatalyst particle is inferior to that corresponding to the homogeneous system, due to the lower substrate concentration compared to its value in the liquid bulk.

The profile of the substrate concentration in this system is plotted in Figure 1.

The values of glucose concentrations at the particle surface and inside the particle can be obtained by means of its mass balance related to a single biocatalyst particle. In this purpose, the following assumptions have been considered:

- the kinetics of the biochemical reaction includes the substrate inhibitory effect;

- the biocatalyst particle is spherical;

- the yeast cells are uniformly distributed inside the particle;

- there are no interactions between the substrate or products and support

- the internal diffusion is described by Fick law and effective diffusivity.

The kinetic model for the bioethanol production is described by the Michaelis-Menten model modified for substrate inhibition [21]:

$$
r=\frac{V \cdot C_{C} \cdot C_{S}}{K_{M}^{\prime}+C_{S}+\frac{C_{S}^{2}}{K_{I}}}
$$

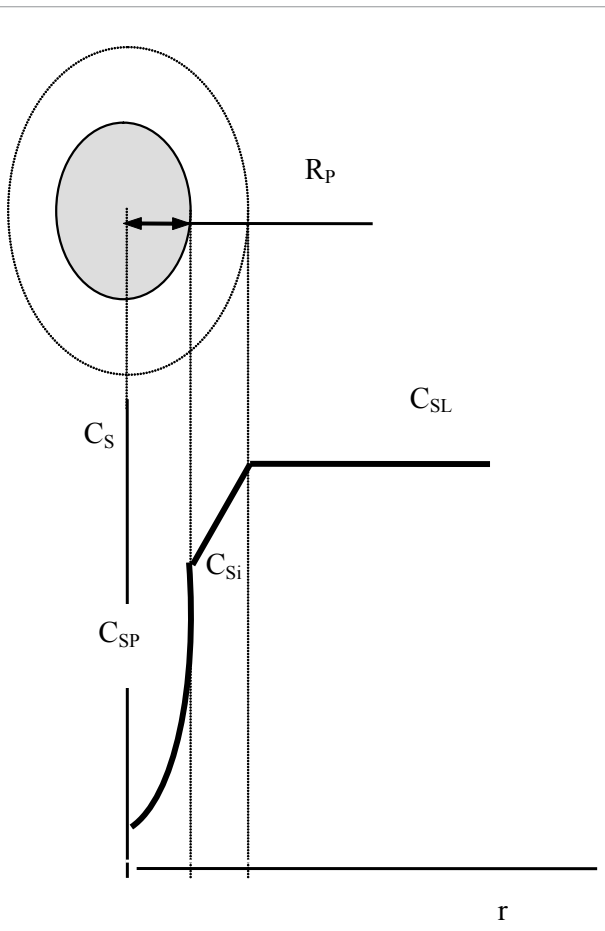

Figure 1: Profile of substrate concentration for a single biocatalyst particle 
Therefore, the expression for the mass balance of glucose related to the biocatalyst particle is:

$$
\frac{d C_{S}}{d t}=D_{S e} \cdot\left[\frac{1}{r^{2}} \cdot \frac{d}{d r}\left(r^{2} \cdot \frac{d C_{S}}{d r}\right)\right]-\frac{V \cdot C_{C} \cdot C_{S}}{K_{M}^{\prime}+C_{S}+\frac{C_{S}^{2}}{K_{I}}}
$$

Considering the steady-state conditions, the equation (2) becomes:

$$
\frac{d^{2} C_{S}}{d r^{2}}+\frac{2}{r} \cdot \frac{d C_{S}}{d r}=\frac{1}{D_{S e}} \cdot \frac{V \cdot C_{C} \cdot C_{S}}{K_{M}^{\prime}+C_{S}+\frac{C_{S}^{2}}{K_{I}}}
$$

and can be solved under the following boundary limits:

$$
\begin{aligned}
& \mathrm{r}=0 \text { (at particle centre), } \frac{d C_{S P}}{d r}=0 \\
& \mathrm{r}=\mathrm{R}_{\mathrm{p}} \text { (at particle surface), }-D_{S e} \cdot \frac{d C_{S P}}{d r}=k_{L} \cdot\left(C_{S L}-C_{S i}\right)
\end{aligned}
$$

In these circumstances, the solution of equation (3) describes the glucose concentration profile inside the biocatalyst particle:

$$
C_{S P}=\frac{R_{p} \cdot \sinh (3 \phi \cdot r)}{r \cdot \cosh \left(3 \phi \cdot R_{p}\right)} \cdot \frac{\left(C_{S L}-C_{S i}\right) \cdot B_{i} \cdot k_{L} \cdot V \cdot C_{C}}{3 \phi \cdot B_{i} \cdot D_{S e}-k_{L} \cdot \tanh \left(3 \phi \cdot R_{p}\right)+K_{I}}
$$

The substrate concentration at the particle surface is obtained using the following relationship:

$$
C_{S i}=\frac{\tanh \left(3 \phi \cdot R_{p}\right) \cdot C_{S L} \cdot B_{i} \cdot k_{L} \cdot V \cdot C_{C}}{3 \phi \cdot B_{i} \cdot D_{S e}+k_{L} \cdot \tanh \left(3 \phi \cdot R_{p}\right) \cdot\left[B_{i} \cdot k_{L} \cdot V \cdot C_{C}-1\right]+K_{I}}
$$

The Thiele modulus, $\phi$, and the Biot number, Bi, quantify the influence of the internal diffusion. Thus, the Thiele modulus indicates the magnitude of the influence of internal diffusion on the biochemical reaction rate [22]. For the studied system, it is defined by the expression:

$$
\phi=\frac{R_{P}}{3} \cdot \sqrt{\frac{V}{K_{M} \cdot D_{S e}}}
$$

The Biot number represents the ratio between the resistance to the diffusion in the boundary layer surrounding the particle and that corresponding to the internal diffusion [22]:

$$
B i=\frac{k_{L} \cdot R_{P}}{D_{S e}}
$$

By means of the substrate concentration values in the liquid bulk and inside the biocatalyst particle, the external and internal mass flows of glucose can be calculated. Therefore, the substrate flux from the liquid phase to the particle surface is:

$$
n_{L}=k_{L} \cdot\left(C_{S L}-C_{S i}\right)
$$

where $k_{L}$ represents the mass transfer coefficient in the boundary layer at the particle surface, being calculated with the expression [23]:

$$
k_{L}=1.90 \cdot \frac{\varphi \cdot(1-\varphi)^{1 / 2} \cdot N^{1 / 2} \cdot \rho_{L}^{1 / 6} \cdot d^{1 / 2} \cdot D_{S L}^{2 / 3}}{\eta_{L}^{1 / 6} \cdot d_{P}^{1 / 2}}
$$

The internal mass flow can be obtained by combining the Fick law:

$$
n_{P}=-D_{S e} \cdot \frac{d C_{S P}}{d r}
$$

with expression (4), resulting the following expression adequate for the fermentation system under substrate inhibition:

$n_{P}=-D_{S e} \cdot \frac{R_{p} \cdot\left(C_{S L}-C_{S i}\right) \cdot B_{i} \cdot k_{L} \cdot V \cdot C_{C} \cdot\left[r \cdot \phi \cdot \cosh \left(3 \phi \cdot R_{p}\right)-\sinh \left(3 \phi \cdot R_{p}\right)\right]}{r^{2} \cdot \cosh \left(3 \phi \cdot R_{p}\right) \cdot\left[3 \phi \cdot B_{i} \cdot D_{S e}-k_{L} \cdot \tanh \left(3 \phi \cdot R_{p}\right)+K_{I}\right]}$
The values of the parameters used for calculating the external and internal mass transfers have been previously established and are given in Table 1 [24-26].

\section{Results and Discussion}

\section{External mass transfer}

Besides the direct influence of glucose concentration in the liquid bulk on its concentration at particle surface, equation (5) suggests that the value of the superficial concentration depends on the size and volumetric fraction of biocatalyst particles. These two parameters exhibit their influences through the consumption rate of substrate.

According to the Figure 2, the increase of the particle diameter leads to the reduction of the ratio between the glucose concentrations at the particle surface and in the liquid bulk, due to the increase of the thickness of the liquid boundary layer and, implicitly, of the resistance to the diffusion towards the particle surface.

This influence is valid only for biocatalysts concentrations up to $25 \%$ vol., over this level the increase of the particle size inducing the increase of the glucose concentration at its surface. In this case, the increase of the biocatalysts concentration determines the increase of the yeast cells concentration and, consequently, the acceleration of the substrate bioconversion rate, effect that is more important for the smallest biocatalyst particles. For this reason, the diminution of the value of superficial concentration of glucose due to the more important resistance to diffusion is partially counteracted by the slower rate of the

\begin{tabular}{|l|l|}
\hline Parameter & Value \\
\hline$D_{S L}$ & $6.47 \times 10^{-10} \mathrm{~m}^{2} \cdot \mathrm{s}^{-1}$ \\
\hline$D_{S e}$ & $4.39 \times 10^{-10} \mathrm{~m}^{2} \cdot \mathrm{s}^{-1}$ \\
\hline$K_{M}{ }^{\prime}$ & $18.14 \mathrm{~kg} \cdot \mathrm{m}^{-3}$ \\
\hline$K_{I}$ & $117.82 \mathrm{~kg} \cdot \mathrm{m}^{-3}$ for $\varphi<0.25$ \\
& $89.48 \mathrm{~kg} \cdot \mathrm{m}^{-3}$ for $\varphi \geq 0.25$ \\
\hline & $6.35 \times 10^{-4} \mathrm{~kg} \cdot \mathrm{m}^{-3} \cdot \mathrm{s}^{-1}$ for $d_{P}=4.0 \mathrm{~mm}$ and $\varphi<0.25$ \\
& $8.68 \times 10^{-4} \mathrm{~kg} \cdot \mathrm{m}^{-3} \cdot \mathrm{s}^{-1}$ for $\mathrm{d}_{P}=4.0 \mathrm{~mm}$ and $\varphi \geq 0.25$ \\
& $4.46 \times 10^{-4} \mathrm{~kg} \cdot \mathrm{m}^{-3} \cdot \mathrm{s}^{-1}$ for $d_{P}=4.6 \mathrm{~mm}$ and $\varphi<0.25$ \\
$V$ & $5.79 \times 10^{-4} \mathrm{~kg} \cdot \mathrm{m}^{-3} \cdot \mathrm{s}^{-1}$ for $\mathrm{d}_{P}=4.6 \mathrm{~mm}$ and $\varphi \geq 0.25$ \\
& $2.27 \times 10^{-4} \mathrm{~kg} \cdot \mathrm{m}^{-3} \cdot \mathrm{s}^{-1}$ for $\mathrm{d}_{\mathrm{P}}=5.2 \mathrm{~mm}$ and $\varphi<0.25$ \\
& $3.16 \times 10^{-4} \mathrm{~kg} \cdot \mathrm{m}^{-3} \cdot \mathrm{s}^{-1}$ for $\mathrm{d}_{\mathrm{P}}=5.2 \mathrm{~mm}$ and $\varphi \geq 0.25$ \\
\hline
\end{tabular}

Table 1: Parameters used for calculations.

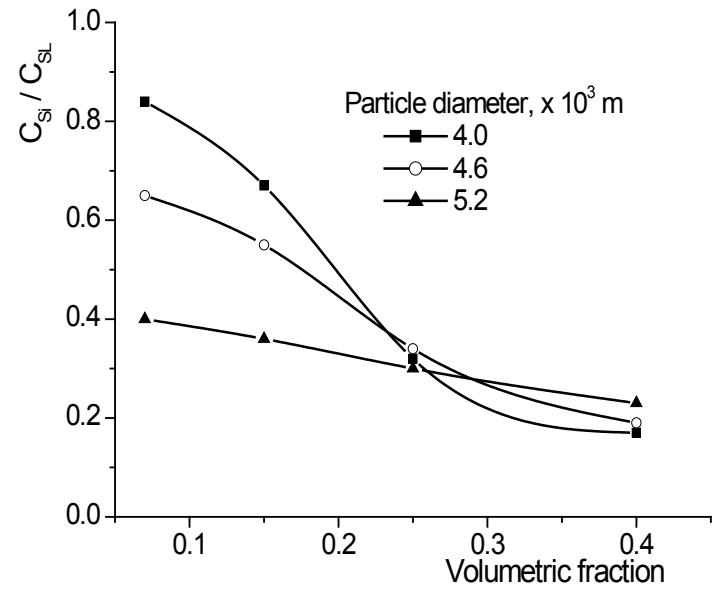

Figure 2: Influence of biocatalyst particles size and volumetric fraction on ratio $\mathrm{C}_{\mathrm{Si}} / \mathrm{C}_{\mathrm{SL}}$ 
biochemical reaction for particles with diameters of 4.6 and $5.2 \mathrm{~mm}$. This conclusion is demonstrated by the highest value of the ratio $\mathrm{C}_{\mathrm{si}} /$ $\mathrm{C}_{\mathrm{SL}}$ obtained at $\varphi=0.40$ for biocatalyst particles with $5.2 \mathrm{~mm}$ diameter.

The negative influence of the amount of biocatalyst particles in the medium on the substrate concentration at the solid surface is the result of the acceleration of the biochemical reaction rate. From Figure 2 it can be observed that by increasing the volumetric fraction of biocatalysts from 0.07 to 0.40 , the ratio $\mathrm{C}_{\mathrm{Si}} / \mathrm{C}_{\mathrm{SL}}$ is reduced from 0.84 to 0.16 for the particles with diameter of $4 \mathrm{~mm}$, from 0.65 to 0.19 for the particles with diameter of $4.6 \mathrm{~mm}$, respectively from 0.40 to 0.23 for the particles with diameter of $5.2 \mathrm{~mm}$.

The dependence between $\mathrm{k}_{\mathrm{L}}$ and the biocatalysts size and concentration is graphically presented in Figure 3.

Figure 3 indicates the negative effect of the particle diameter on the mass transfer coefficient through the liquid boundary layer surrounding the particle, owing to the increasing of this layer thickness. The particles concentration exhibits a contrary influence, its increase leading to the increase of $\mathrm{k}_{\mathrm{L}}$. This result can be attributed to the acceleration of glucose bioconversion rate at higher amount of biocatalysts and, therefore, to the increase of the glucose concentration gradient between the liquid bulk and particle surface.

The external mass flow of glucose has been calculated by introducing the values of the above discussed parameters in equation (8), considering the glucose concentration in liquid equal with its initial concentration $\left(100\right.$ g. $\left.\mathrm{L}^{-1}\right)$. In this context, Figure 4 underlines the decisive role of the volumetric fraction of biocatalysts on the variation of glucose mass flow with biocatalysts diameter.

Therefore, at volumetric fraction below 0.25 , the mass flow increases with the increase of particles size, due to the amplification of the substrate concentration gradient inside the liquid boundary layer. The sense of this variation is modified for more concentrated suspensions of biocatalysts, as the result of the increase of substrate superficial concentration and, implicitly, of the diminution of its concentration gradient for larger particles.

\section{Internal mass transfer}

Because the glucose concentration inside the biocatalyst particle depends strongly on its concentration at the particle surface, the variation of the ratio between these two concentrations with the particle radius can describe more accurately the influence of the internal diffusion. From Figure 5 it can be seen that the ratio $\mathrm{C}_{\mathrm{SP}} / \mathrm{C}_{\mathrm{Si}}$ is significantly reduced to the particle centre, this effect being more pronounced for biocatalyst particles with higher diameters.

Thus, the value of this ratio decreases from 1 to 0.048 for the smallest particles, to 0.042 for the medium particles, and to 0.035 for the largest ones, respectively. This variation is not affected by the modification of biocatalysts concentration in the medium.

In this circumstances, function of the superficial concentration of glucose and biocatalysts concentration, the glucose concentration at the particle centre could reach a very low value compared to that from the liquid bulk, this becoming an important threat for the normal alcoholic fermentation process. Due to the increase of the magnitude of diffusional resistance for the larger particles, at low volumetric fraction $(\varphi=0.07)$, the central substrate concentration for particles with $4 \mathrm{~mm}$ diameter is for about 1.4 times greater than that for particles with $4.6 \mathrm{~mm}$ diameter, respectively for about 2.8 times greater than that corresponding to the particles having the diameter of $5.2 \mathrm{~mm}$.

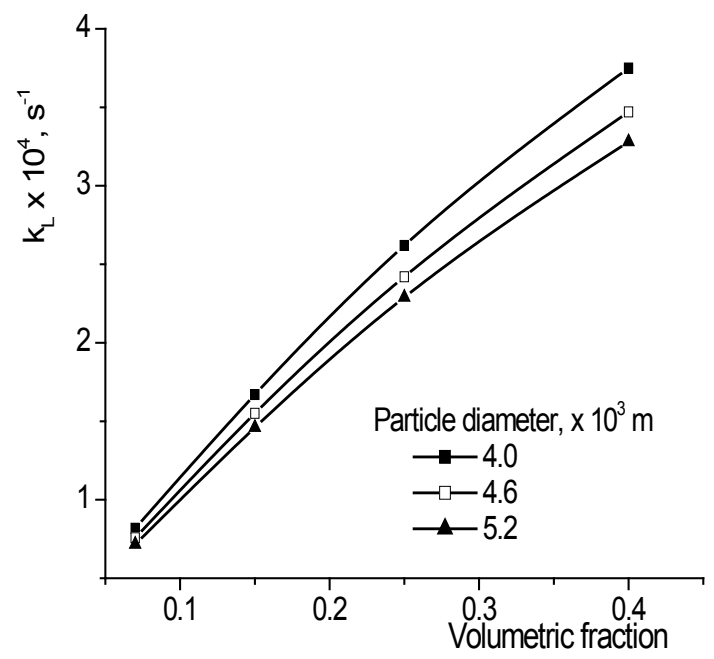

Figure 3: Influence of biocatalyst particles size and volumetric fraction on $\mathrm{k}_{\mathrm{L}}$

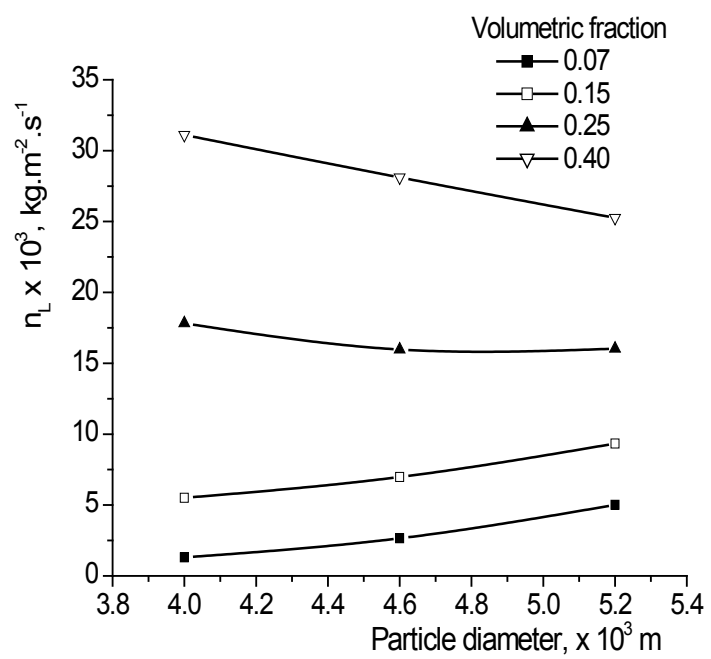

Figure 4: Influence of biocatalyst particles size and volumetric fraction on external glucose mass flow.

For concentrated suspensions $(\varphi=0.40)$, the values of the central concentrations for the three sizes of biocatalysts are comparable, owing to the high bioconversion rate of glucose which compensates the differences between the substrate diffusion velocities in these particles.

By means of the equation (11) and using the above presented data, the values of the internal mass flow of glucose have been estimated. The variation of internal mass flow with the biocatalyst radius is plotted in Figure 6.

The primary analysis of the plotted curves indicates that the values of the internal mass flow are for about $10^{6}$ times lower than those recorded for the external mass flow. Moreover, Figure 6 shows the direct correlation between the internal mass flow and substrate concentration; both being significantly reduced nearly the particle centre. Indifferent of the particle size, for certain inner position and 
biocatalysts concentration, the highest levels of internal mass flow have been reached for the smallest particles, owing to the lowest resistance to the substrate internal diffusion. This order of variation has been maintained also at higher concentration of biocatalysts, but with the pronounced reduction of the mass flow, for the above discussed reasons (at a distance of $1.5 \mathrm{~mm}$ from the particle centre, the mass flow estimated for $\varphi=0.40$ was lower than that for $\varphi=0.07$ for about 4.9 times for particles with $4 \mathrm{~mm}$ diameter, 3.4 times for particles with $4.6 \mathrm{~mm}$ diameter, 1.8 times for particles with $5.2 \mathrm{~mm}$, respectively).

Taking into consideration the order of magnitude of effective diffusivity, it can be assumed that for values of internal mass flow lower than $4 \times 10^{-10} \mathrm{~kg} \cdot \mathrm{m}^{-2} \cdot \mathrm{s}^{-1}$ the mass transfer of glucose is insignificant. Therefore, the glucose mass flow becomes negligible for the largest particles in a region with radius of $0.1 \mathrm{~mm}$ for $\varphi=0.07$, respectively in a region with radius of $0.6 \mathrm{~mm}$ for $\varphi=0.40$. For the smaller particles, only at a volumetric fraction of 0.40 the internal mass flow reaches values below $4 \times 10^{-10} \mathrm{~kg} \cdot \mathrm{m}^{-2} \cdot \mathrm{s}^{-1}$, in a region with radius of $0.3 \mathrm{~mm}$ for particles with $4 \mathrm{~mm}$ diameter, and with radius of $0.5 \mathrm{~mm}$ for particles with 4.6

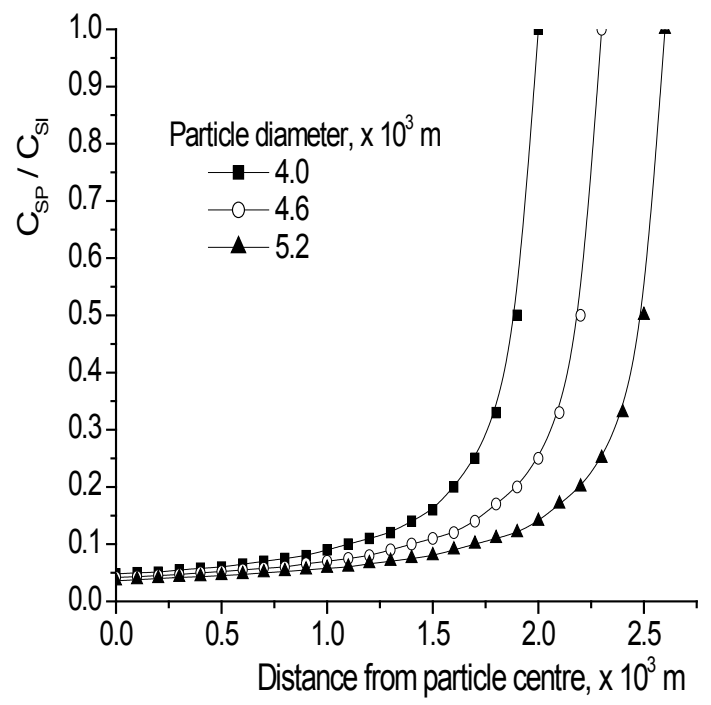

Figure 5: Variation of ratio $\mathrm{C}_{\mathrm{SP}} / \mathrm{C}_{\mathrm{Si}}$ with distance from the particle centre.

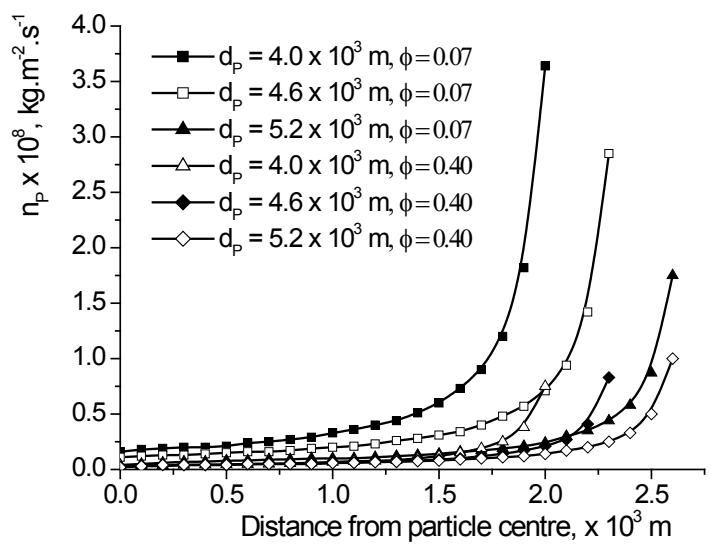

Figure 6: Variation of internal glucose mass flow with distance from the particle centre. $\mathrm{mm}$ diameter. In all these cases, a region representing between 0.34 and $1.22 \%$ from the overall particles volume could be considered as a "biological inactive region". Because the experimented bioreactor is with mobile beds of immobilized biocatalysts, the extent of this region is significantly diminished compared to that previously reported for similar fermentation using a fixed bed bioreactor (due to the reduced substrate concentration at the biocatalyst particle surface for the second type of bioreactor, as the result both of the increased turbulence around the particles for the stirred bed bioreactor and to the diffusion inside the packed bed for the fixed bed bioreactor) [22].

\section{Conclusions}

The alcoholic fermentation using a bioreactor with mobile beds of immobilized S. cerevisiae cells on alginate has been analyzed under substrate inhibition conditions. The studies have been focused on the external and internal mass transfer of glucose and, implicitly, on the influence of the internal diffusion on the transfer and biochemical processes. The experiments have been carried out for different sizes and concentrations of biocatalysts particle.

In this purpose, a specific mathematical model has been developed taking into account the substrate mass balance for a single particle and its inhibitory effect, being used for calculating the glucose concentrations at the surface and inside the biocatalyst. Using these concentration values, the glucose mass flows through the liquid boundary film surrounding the particle and inside the particle have been estimated. The influence of the particles size on the substrate mass flows has to be analyzed in direct relation with the volumetric fraction of the particles in the medium, due to the significant dependence between the biochemical reaction rate and biocatalysts concentration.

The variation of internal mass flow of glucose with particle radius indicated that it is possible to be reached very low values of mass flow nearly the particle centre, values that could be negligible. The region inside the particle corresponding to the insignificant mass transfer of glucose could be considered "biological inactive region", its magnitude varying from 0.34 to $1.22 \%$ from the overall volume of particles. But, this extend of the dead region is considerably lower than that observed in the bioreactor with fixed bed of immobilized yeast cells.

\section{References}

1. Cascaval D, Galaction Al (2007) The European color of biotechnology is white. Rom Biotechnol Lett 12: 3489-3494.

2. Takamitsu I, Izumida H, Akagi Y, Sakamoto M (1993) Continuous ethano fermentation in molasses medium using Zymomonas mobilis immobilized in photo-cross linkable resin gels. J Ferment Bioeng 75: 32-35.

3. Najafpour G, Younsei H, Syahidah K, Ismail K (2004) Ethanol fermentation in an immobilized cell reactor using S. cerevisiae. Bioresour Technol 92: 251-260.

4. Staniszewski M, Kujawski W, Lewandowska M (2009) Semi-continuous ethanol production in bioreactor from whey with co-immobilized enzyme and yeast cells followed by pervaporative recovery of product - kinetic model predictions considering glucose repression. J Food Eng 91: 240-249.

5. Bailey JF, Ollis DF (1986) Biochemical engineering fundamentals. McGrawHill, New York.

6. Ingram LO, Gomez PF, Lai X, Moniruzzaman M, Wood BE, et al. (1998) Metabolic engineering of bacteria for ethanol production. Biotechnol Bioeng 58: $204-214$

7. Nagodawithana TW, Steinkraus KH (1976) Influence of the rate of ethano production and accumulation on the viability of Saccharomyces cerevisiae in rapid fermentation. Appl Environ Microbiol 31: 158-162.

8. Yamada T, Fatigati MA, Zhang M (2002) Performance of immobilized Zymomonas mobilis 31821 (pZB5) on actual hydrolysates produced Arkeol technology. Appl Biochem Biotechnol 98: 899-907. 
Citation: Galaction A, Turnea M, Cascaval D (2012) Glucose Mass Transfer in Alcoholic Fermentation Using Stirred Beds of Immobilized S. Cerevisiae Cells. Single Cell Biol 1:101. doi:10.4172/ 2168-9431.1000101

Page 6 of 6

9. Nigam JN (2000) Continuous ethanol production from pineapple cannery waste using immobilized yeast cells. J Biotechnol 80: 189-193.

10. Williams D, Munnecke DM (1981) The production of ethanol by immobilized yeast cells. Biotechnol Bioeng 23: 1813-1825.

11. Rivaldi JD, Sarrouh BF, da Silva SS (2008) An evaluation of different bioreactor configurations with immobilized yeast for bioethanol production. Int $\mathrm{J}$ Chem Reactor Eng 6: 115.

12. Pacheco AM, Gondim DR, Gonçalves LR (2010) Ethanol production by fermentation using Immobilized cells of Saccharomyces cerevisiae in cashew apple bagasse. Appl Biochem Biotechnol 161: 209- 217.

13. Nikolic S, Mojovic L, Rakin M, Pejin D (2009) Bioethanol production from corn meal by simultaneous enzymatic saccharification and fermentation with immobilized cells of Saccharomyces cerevisiae varellipsoideus. Fuel 88: 16021607.

14. Singh NL, Srivastava P, Mishra PK (2009) Studies on ethanol production using immobilized cells of Kluyveromyces thermotolerans in a packed bed reactor. $J$ Scientif Ind Res 68: 617-623.

15. Behera S, Kar S, Mohanty RC, Ray RC (2010) Comparative study of bio-ethano production from mahula (Madhuca latifolia L.) flowers by Saccharomyces cerevisiae cells immobilized in agar agar and Ca-alginate matrices. Appl Energy 87: 96-100.

16. Galaction AI, Lupasteanu AM, Cascaval D (2007) Bioreactors with stirred bed of immobilized cells1Studies on mixing efficiency. Environ Eng Manag J 6: 101 110.

17. Galaction Al, Lupăşteanu AM, Turnea M, Caşcaval D (2010) Comparative analysis of mixing efficiency and distribution induced by radial impellers in bioreactors with stirred beds of immbilized cells. Chem Ind Chem Eng Quart 16: 47-64

18. Galaction AI, Caşcaval D, Turnea M, Folescu E (2005) Enhancement of oxygen mass transfer in stirred bioreactors using oxygen-vectors: 2 - Propionibacterium shermanii broths. Bioproces Biosyst Eng 27: 263-271.

19. Caşcaval D, Galaction Al, Folescu E, Turnea M (2006) Comparative study on the effects of $n$-dodecane addition on oxygen transfer in stirred bioreactors for simulated, bacterial and yeasts broths. Biochem Eng J 31: 56-66.

20. Aiba S, Shoda M, Nagatani M (1968) Kinetic product inhibition in alcohol fermentation. Biotechnol Bioeng 10: 845-864.

21. Doble M, Kruthiventi AK, Gaikar VG (2004) Biotransformations and bioprocesses. MDekker, Inc, New York.

22. Zaiat M, Rodrigues JAD, Foresti E (2000) External and internal mass transfer effects in an anaerobic fixed-bed reactor for wastewater treatment. Process Biochem 35: 943-949.

23. Perry RH, Chilton CH (1973) Chemical Engineers Handbook. (5th edn) McGraw-Hill, New York.

24. Vicente AA, Dluhy M, Ferreira EC, Mota M, Teixeira JA (1998) Mass transfer propeties of glucose and $\mathrm{O}_{2}$ in Scerevisiae flocs. Biochem Eng J 2: 35-43.

25. Estape D, Godia F, Sola C (1992) Determination of glucose and ethano diffusion coefficients in Ca-alginate gel. Enzyme Microb Technol 14: 396-401.

26. Galaction AI, Lupasteanu AM, Cascaval D (2010) Kinetic studies on alcoholic fermentation under substrate inhibition conditions using a bioreactor with stirred bed of immobilized yeast cells. Open System Biol J 3: 09-20. 